\title{
Development and characterization of chitosan and beeswax coated biodegradable corn husk and sugarcane bagasse-based cellulose paper.
}

Aastha Bhardwaj

Nitya Sharma

IIT Delhi: Indian Institute of Technology Delhi

Tanweer Alam

IIP Mumbai: Indian Institute of Packaging

Vasudha Sharma

Jamia Hamdard

J.K. Sahu

IIT Delhi: Indian Institute of Technology Delhi

Hinna Hamid ( $\sim$ hhamid@jamiahamdard.ac.in )

Jamia Hamdard https://orcid.org/0000-0003-4813-297X

Vasudha Bansal

Government Home Science College

sarwar Alam

Jamia Hamdard

\section{Research Article}

Keywords: Biodegradable, Packaging, Beeswax, Chitosan, Sugarcane bagasse, Corn husk

Posted Date: March 7th, 2022

DOl: https://doi.org/10.21203/rs.3.rs-1403015/v1

License: (c) (i) This work is licensed under a Creative Commons Attribution 4.0 International License. Read Full License 


\section{Abstract}

This research focuses on the development of paper from lignocellulosic agricultural wastes, viz., corn husk $(\mathrm{CH})$, which is an underexplored material and sugarcane baggase (SB), in varying proportions, through soda pulping and enhancement of their functionalities through chitosan and chitosan-beeswax emulsion coatings. Fiber digestion conditions were as follows: $100^{\circ} \mathrm{C}(30 \mathrm{~min}) ; 100-162^{\circ} \mathrm{C}(90 \mathrm{~min})$ and $162^{\circ} \mathrm{C}(90 \mathrm{~min})$; followed by blowing, quenching and then refining of both treated $\mathrm{CH}$ and SB pulp to a Canadian Standard Freeness (CSF) of 400-450 mL. The handsheets of 80 GSM (grammage) were prepared as per the standard ISO-5269/1 and were tested for their mechanical and barrier properties as per standard methods of ISO. Handsheets developed from the blend of SB and $\mathrm{CH}$ (50:50) and SB fibers (100\%) were found to have better mechanical strength (in terms of burst, tensile and tear strength) in comparison to $\mathrm{CH}$ fibers (100\%). The effect of coatings on mechanical, water resistance, micro-structural, and biodegradable properties of the cellulose papers were also assessed. The chitosan coating significantly improved $(p<0.05)$ the mechanical properties of papers, the barrier properties against water vapor, moisture and air were also enhanced (up to 85\%). Papers coated with beeswax-chitosan emulsion had the longest absorbency time, followed by chitosan-coated and uncoated papers. The results advocated for beeswax-chitosan emulsion as the best among the coatings tested, for aforementioned cellulose papers to enhance their barrier properties.

\section{Introduction}

Paper and pulp-based packaging has gained prominence over plastic packaging in the last two decades, owing to the fact that plastics pose a grave environmental concern due to their non-biodegradability. With the emergence of modern retail formats where the visual appeal, shelf life and unique brand identity have taken a center stage, the paper and paperboard sector provide a long-standing commitment to the protection of human and environmental health. The paper industry relies on different raw materials viz. wood, agro-residues, and recycled fibers to meet the demand for paper and pulp. However, the depleting forest cover has declined the supply of wood to the industry. Thereby, non-wood fibers present an excellent low-cost substitute for pulp and paper making to meet the increasing paper demand. Stubble burning is another major problem in northern states of India, adversely affecting human health which needs to be addressed. In India, the annual production of crop residues is about 500 million tons, the majority of which is used for fodder, fuel and other industrial purposes [1]. However, out of the surplus of 140 million tons, over 90 million tons of the residues are burnt in open fields [1-2]. Smoke emissions from the burning of residues create a toxic cloud over the cities, which ultimately results in air pollution emergencies, often evidenced in breathing and respiratory problems of people. Developing packaging materials from renewable and bio-based sources has thus become quintessential, not only to combat problems of waste disposal but also, to impede stubble burning and facilitate fruitful conservation of wood resources [3].

Sugarcane bagasse (SB) is found to be one of the best alternatives of wood for papermaking because of its abundance, low cost, long fiber length, low refining energy consumption, good sheet formation ability and smoothness [4], while corn husks $(\mathrm{CH})$, being shorter in length, are still underexplored and have been the subject of a very limited amount of research interest as a fiber source. Literature survey reveals that ample studies have been carried out on the pulping characteristics of sugarcane bagasse with other agro-residues, 
viz., bamboo, mixed hardwoods and softwoods for manufacturing of different grades of pulps. Thus, an effort has been made to explore the papermaking potential of $\mathrm{CH}$ fibers as a whole and as a furnish blend with $\mathrm{SB}$.

Papers, in general, are ascribed with poor strength and barrier properties, in comparison to plastics. Several alternative green bio-coating solutions such as sodium alginate, shellac, chitosan, beeswax etc. have been explored as coatings on fibrous papers to improve their mechanical strength and barrier properties [5-7], thereby opening new avenues of their use and applications in the packaging industry.

Chitosan and its additives are known to impart improved strength such as higher burst and tensile strength to paper based materials. Additionally, they enhance the air and water resistance of paper-based packaging by increasing the contact angle between water droplets and paper surface [8]. Similarly, beeswax-chitosan emulsion, being lipophilic in nature, imparts a characteristic resistance to the paper surfaces against moisture and air. Thus, this research not only aims at developing papers using less explored fibers but also aims at studying the effect of food-grade coatings namely, chitosan and chitosan-beeswax emulsion, on the mechanical, barrier and microstructural properties of aforementioned papers developed from agricultural biomass.

\section{Materials \& Methods}

\section{Procurement of raw materials and chemicals}

$\mathrm{CH}$ residue left after corn cob removal was collected from the local markets of Delhi, India. SB residue was obtained from a sugar processing mill in the vicinity of Delhi, India. Raw materials were washed thoroughly to remove dirt and soil and were dried in a hot air oven to a moisture level of $10 \pm 2 \%$. Raw materials were then chopped (5-7 cm long) and stored in polyethylene bags at $4{ }^{\circ} \mathrm{C}$ for later use.

Sodium hydroxide, glycerol and acetic acid for delignification and coating preparations were obtained from Merck India. Food grade chitosan powder (CAS 9012-76-4), with a deacetylation degree of $>88 \%$ and particle size of $400 \mu$, was purchased from Everest Biotech Pvt. Ltd., Bengaluru, India. Food grade refined Beeswax (in the form of pellets) was procured from Ms/ S.K. International, India.

\section{Digestion process and experimental formulations}

The shreds of $\mathrm{CH}$ and $\mathrm{SB}$ were taken in varying proportions and delignified using the conventional method of soda $(\mathrm{NaOH})$ pulping [9]. The samples were digested in a laboratory digester (Pulping unit Model Number: GECP40314, Global Engineering Corporation, India) consisting of six bombs rotating in an electrically heated polyethylene glycol (PEG) bath. Before cooking, the moisture content of the samples was determined using the

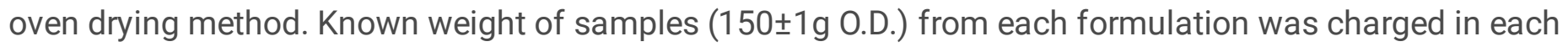
bomb with $10 \% \mathrm{NaOH}$, while keeping the digestion time and temperature constant. The liquid to raw material ratio was kept at 5:1. The bombs were then tightly closed and placed into the heated glycol bath under rotation. All the bombs were run simultaneously. The glycol bath had a range of working temperatures between $80^{\circ} \mathrm{C}$ and $170^{\circ} \mathrm{C}$. Cooking conditions were set and monitored by digital temperature control (DTC) system as follows: $100^{\circ} \mathrm{C}(30 \mathrm{~min}) ; 100-162^{\circ} \mathrm{C}(90 \mathrm{~min})$ and $162^{\circ} \mathrm{C}(90 \mathrm{~min})$. After cooking, the bombs were quenched by spraying cold water on them for $5 \mathrm{~min}$. Pulps were taken out and thoroughly washed in a cylindrical vessel with 
warm water, until the mass was free from black liquor, followed by fibrillation/refining in a PFI mill (Universal Engineering Corporation, India) (as per ISO-5264) [10] to achieve a level of Canadian Standard Freeness (CSF) of 400-450 ml. Table 1 shows the selected pulp formulations (\% wet weight) chosen for handsheet development. Henceforth the papers developed from these pulp formulations were designated as paper $A$ (from $100 \%$ SB); paper B (from 50:50 SB: CH blend) and paper C (from 100\% corn husk).

\section{Table 1: Pulp formulations for hand sheet development}

\begin{tabular}{llll} 
Raw & \multicolumn{3}{l}{ Pulp Formulations (\% wet weight) } \\
\cline { 2 - 4 } Material & Paper A & Paper B & Paper C \\
\hline SB & 100 & 50 & 0 \\
\hline CH & 0 & 50 & 100
\end{tabular}

SB: Sugarcane bagasse; $\mathrm{CH}$ : Corn husk

Paper A: Paper from SB fibers only; Paper B: Paper from SB: CH (50:50) as furnish blend; Paper C: Paper from $\mathrm{CH}$ fibers only.

\section{Preparation and testing of laboratory scale handsheets}

Laboratory handsheets of 80 GSM were formed in a British handsheet former (Universal Engineering Corporation, India) (ISO-5269/1: 2005) [11]. The sheets were conditioned for 24 hours at $27 \pm 1^{\circ} \mathrm{C}$ and $65 \pm 2 \%$ relative humidity $(\mathrm{RH})$ in the National Accreditation Board for Testing and Calibration Laboratories (NABL), India accredited paper testing facility at Central Pulp \& Paper Research Institute (CPPRI), Saharanpur, Uttar Pradesh (India), and were tested for their mechanical and barrier properties. Properties viz tensile strength and breaking length (ISO 1924-2: 2008) [12], zero span tensile strength (ZSTS) (ISO-15754:2009) [13], burst strength (ISO-2758: 2014) [14], tear strength (ISO-1974: 2012) [15], porosity (ISO 5636-5) [16] and water absorptiveness (Cobb test at 60 seconds: ISO-535: 2014) [17] were tested according to standard methods of ISO. Tensile strength, tear strength and burst strength were expressed as their respective indices. Water vapor permeability was assessed as per the method specified by Nurul Syahida et al [18]. All tests were conducted in triplicates.

\section{Preparation of coating solutions, coating application and subsequent testing of handsheets}

Food grade chitosan $(2 \% \mathrm{w} / \mathrm{v})$ was prepared by dissolving in $1 \%$ acetic acid $(\mathrm{v} / \mathrm{v})$ by continuous stirring at $700-$ $900 \mathrm{rpm}$ for 2-4 hrs at room temperature (RT) [19]. Cellulose paper sheets (A, B, C) were coated using this chitosan solution equivalent to $2.0-2.5 \mathrm{gm}^{-2}$, using a wire bar coater (TKB Erichsen, Brazil), with a coating speed of $10 \mathrm{~m} / \mathrm{min}$ and were air-dried for an hour. For beeswax coating preparation, the method of Zhang et al [20] with certain modifications was employed. Chitosan solution ( $1 \% \mathrm{w} / \mathrm{v})$ was prepared in a manner similar to earlier, followed by the addition of glycerol (4:1). This solution was then heated up to around $80{ }^{\circ} \mathrm{C}$ in a water bath to melt the respective amount of beeswax. The weight of beeswax was added in such a way that it occupied $30 \mathrm{wt} \%$ of the emulsion film dry matter. The solution was then homogenized at 12,000 rpm using a Lab Scale High Shear Homogenizing Emulsifier (RH-C, 220V, 50/60Hz, Manu Enterprises, India). Next, the emulsion thus formed, was then cooled to room temperature and the cellulose papers (A, B, C) were coated 
using this solution likewise and held for drying at room temperature for an hour. All coated handsheets were further subjected to mechanical and barrier testing. All tests were conducted in triplicates.

\section{Chemical groups identification using Fourier transform infrared spectroscopy (FT-IR)}

The FT-IR spectra of the coated papers was collected using a Nicolet iZ10 FT-IR spectrometer (Thermo Fisher Scientific, Wisconsin, USA) with an attached attenuated total reflectance accessory. The employed spectral range was within $4000-500 \mathrm{~cm}^{-1}$ and the resolution was $4.0 \mathrm{~cm}^{-1}$. No specific preparation was required for the analysis of paper samples.

\section{Surface morphology of the papers using scanning electron microscopy (SEM)}

The surface topography of uncoated and coated handsheets was investigated using scanning electron microscopy (SEM, Everhart-Thornley detector for the detection of secondary electrons; Carl Zeiss EVO 50, Germany). The paper samples of $1 \mathrm{~cm}^{2}$ dimensions were cut and attached to SEM stubs using a double-sided conductive carbon tape and imaging was performed at an electron high tension (EHT) voltage of $20 \mathrm{kV}$.

\section{Biodegradability}

The biodegradability of developed papers (coated and uncoated) was checked using the soil burial method as described by Yaradoddi et al [21] with slight modifications. Paper samples of dimensions $\left(4 * 4 \mathrm{~cm}^{2}\right)$ were weighed and were placed at least $8-10 \mathrm{~cm}$ beneath the soil to ensure contact of the paper samples with soil from all sides. The soil was sprayed with $20 \pm 1 \mathrm{~mL}$ of water every day and the buried paper was analysed for 50 days at $24 \pm 4{ }^{\circ} \mathrm{C}$. Weight loss was measured for each paper sample by removing it from the soil every 10 days, carefully dusting off dirt/soil particles using a tissue and then drying the paper samples at $40{ }^{\circ} \mathrm{C}$. This process was carried out every 10 days until a constant weight for each paper sample was obtained. The analysis was conducted in triplicates. The overall biodegradation rate was expressed as a percentage of weight loss (\%).

\section{Statistical analysis}

Statistical analysis was conducted by using Minitab 17 software (Minitab Inc., USA) to perform a one-way analysis of variance (ANOVA). The significant differences between samples were determined by using Tukey's multiple-range test at a $95 \%$ confidence level.

\section{Results \& Discussion}

\section{Fourier transform infrared spectroscopy}

Molecular interactions of the chitosan and chitosan-beeswax emulsion coating with developed cellulose papers were determined using ATR-FTIR analysis and the spectra are shown in Fig. 2. The structure of chitosan is very close to cellulose; the bands at $3500-3200 \mathrm{~cm}^{-1}$ were attributed to stretching of free-OH groups as well as inter-molecular hydrogen bonds in the spectra of all the developed papers (Fig. 2). Chitosan coating led to the broadening of these absorptions due to hydrogen bonding interactions. The absorption peaks at 2820$2930 \mathrm{~cm}^{-1}$ represent the stretching vibration of $\mathrm{C}-\mathrm{H}$ bonds which show enhanced peak intensity in chitosan- 
coated papers (Polat et al. [22]. The characteristic peaks of chitosan were observed due to $\mathrm{C}=\mathrm{O}$ amide I stretching vibration or introduced by bonded water deformation at $1650 \mathrm{~cm}^{-1}$ and amide II N-H bending vibration at and near $1553 \mathrm{~cm}^{-1}$, respectively. The appearance of the distinguishing peak at $1553 \mathrm{~cm}^{-1}$ is an indication of the presence of chitosan. The bands at 1150 and $1080 \mathrm{~cm}^{-1}$ represent C-O-C and pyranose units on the chitosan structure, respectively [23]. A peak at $1406 \mathrm{~cm}^{-1}$ has been assigned to stretching bands of C-N. However, for beeswax coating, strong peaks were found at $2900-2812 \mathrm{~cm}^{-1}$ for $-\mathrm{CH}$ stretching vibration along with peaks at $1730 \mathrm{~cm}^{-1}$ ascribed to the presence of aliphatic aldehydes. Also, $\mathrm{CH}_{2}$ scissor vibration bands appeared at 1472 and $1462 \mathrm{~cm}^{-1}$ and bands around 700 and $730 \mathrm{~cm}^{-1}$ exhibited distortion of $\mathrm{CH}_{2}$ groups. The minimized hump in the bands of $3500-3000 \mathrm{~cm}^{-1}$ due to $-\mathrm{OH}$ group is also indicative of the presence of beeswax coating.

\section{Mechanical and barrier properties}

Pre-coating: Table 2 shows the results for physico-mechanical properties of developed handsheets from the three previously mentioned formulations. The burst index of paper A and paper B developed from $100 \%$ SB and 50:50 (SB: $\mathrm{CH}$ ), respectively, were found to be reasonably high. The highest burst index was observed for paper B, i.e., $2.81 \pm 0.04 \mathrm{kPa} \cdot \mathrm{m}^{2} \mathrm{~g}^{-1}$, while the lowest was seen for paper $\mathrm{C}(100 \% \mathrm{CH})$, i.e., $0.65 \pm 0.05 \mathrm{~g} \mathrm{kPa} \cdot \mathrm{m}^{2} \mathrm{~g}^{-1}$. Interestingly, paper A outshined paper B and $\mathrm{C}$, in terms of tear and tensile strength. The higher tear and tensile strength were presumably due to the higher proportion of longer fibers in SB pulp. The tensile strength of the paper from pulp is much dependent on the quality and quantity of fiber cellulose and hemicellulose, which are carriers of the $-\mathrm{OH}$ group responsible for hydrogen bonding in paper [24]. High tensile strength of paper $\mathrm{A}$ $\left(77.91 \pm 0.56 \mathrm{Nm} \mathrm{g}^{-1}\right)$ and paper $B\left(55.00 \pm 0.80 \mathrm{Nm} \mathrm{g}^{-1}\right)$, may be attributed to the presence of higher cellulose content in sugarcane bagasse fibers, while the least value of tensile strength of paper $C\left(21.17 \pm 0.59 \mathrm{Nm} \mathrm{g}^{-1}\right)$ was supposedly due to shorter fiber length and relatively lower cellulose content. Breaking length of packaging material is also related to its tensile strength and ascertains about the maximum amount of tensile stress the material can endure before its failure [25]. ZSTS test provides a quick, reliable means to measure the zero-span tensile strength of a randomly oriented specimen of fibers when dry. It is a good indicator of the average strength of the individual fiber [26]. ZSTS value for papers A, B and C was found to be $11.5 \pm 0.07 \mathrm{~km}, 7.60 \pm$ $0.06 \mathrm{~km}$ and $3.85 \pm 0.05 \mathrm{~km}$, signifying the highest individual fiber strength of $\mathrm{SB}$ and least for $\mathrm{CH}$, while paper $\mathrm{B}$ demonstrated an intermediate value due to the presence of both fibers. 
Table 2

Mechanical properties of handsheets (pre and post coating)

\begin{tabular}{|c|c|c|c|c|c|c|c|c|c|}
\hline \multirow[t]{2}{*}{ Parameters } & \multicolumn{3}{|l|}{ Paper A } & \multicolumn{3}{|l|}{ Paper B } & \multicolumn{3}{|l|}{ Paper C } \\
\hline & Uncoated & $\mathrm{CC}$ & wc & Uncoated & $\mathrm{CC}$ & WC & Uncoated & $\mathrm{CC}$ & WC \\
\hline $\begin{array}{l}\text { Burst Index } \\
\text { (kPa.m }{ }^{2} \mathrm{~g}^{-} \\
\left.{ }^{1}\right)\end{array}$ & $\begin{array}{l}2.41 \pm \\
0.07^{d}\end{array}$ & $\begin{array}{l}4.40 \\
\pm \\
0.05^{\mathrm{a}}\end{array}$ & $\begin{array}{l}2.49 \\
\pm \\
0.08^{d}\end{array}$ & $\begin{array}{l}2.81 \pm \\
0.04^{c}\end{array}$ & $\begin{array}{l}4.48 \\
\pm \\
0.08^{\mathrm{a}}\end{array}$ & $\begin{array}{l}2.92 \\
\pm \\
0.06^{\mathrm{b}}\end{array}$ & $\begin{array}{l}0.65 \pm \\
0.05^{9}\end{array}$ & $\begin{array}{l}1.03 \\
\pm \\
0.07^{\mathrm{e}}\end{array}$ & $\begin{array}{l}0.98 \\
\pm \\
0.04^{f}\end{array}$ \\
\hline $\begin{array}{l}\text { Tear index } \\
\left(\mathrm{mN} \cdot \mathrm{m}^{2} \mathrm{~g}^{-}\right. \\
\left.{ }^{1}\right)\end{array}$ & $\begin{array}{l}7.10 \pm \\
0.09^{b}\end{array}$ & $\begin{array}{l}7.24 \\
\pm \\
0.08^{a}\end{array}$ & $\begin{array}{l}7.17 \\
\pm \\
0.10^{\mathrm{b}}\end{array}$ & $\begin{array}{l}6.57 \pm \\
0.08^{d}\end{array}$ & $\begin{array}{l}6.88 \\
\pm \\
0.10^{c}\end{array}$ & $\begin{array}{l}6.60 \\
\pm \\
0.07^{d}\end{array}$ & $\begin{array}{l}4.41 \pm \\
0.08^{f}\end{array}$ & $\begin{array}{l}4.67 \\
\pm \\
0.08^{\mathrm{e}}\end{array}$ & $\begin{array}{l}4.40 \\
\pm \\
0.09^{f}\end{array}$ \\
\hline $\begin{array}{l}\text { Tensile } \\
\text { Index (Nm } \\
\left.\mathrm{g}^{-1}\right)\end{array}$ & $\begin{array}{l}77.91 \pm \\
0.56^{\mathrm{c}}\end{array}$ & $\begin{array}{l}85.10 \\
\pm \\
0.71^{\mathrm{a}}\end{array}$ & $\begin{array}{l}81.02 \\
\pm \\
0.89^{b}\end{array}$ & $\begin{array}{l}55.00 \pm \\
0.80^{f}\end{array}$ & $\begin{array}{l}59.55 \\
\pm \\
0.62^{d}\end{array}$ & $\begin{array}{l}57.10 \\
\pm \\
0.71^{\mathrm{e}}\end{array}$ & $\begin{array}{l}21.17 \pm \\
0.59^{h}\end{array}$ & $\begin{array}{l}24.00 \\
\pm \\
0.52^{\mathrm{g}}\end{array}$ & $\begin{array}{l}21.99 \\
\pm \\
0.55^{\mathrm{h}}\end{array}$ \\
\hline $\begin{array}{l}\text { Breaking } \\
\text { length (km) }\end{array}$ & $\begin{array}{l}7.94 \pm \\
0.15^{c}\end{array}$ & $\begin{array}{l}8.68 \\
\pm \\
0.16^{a}\end{array}$ & $\begin{array}{l}8.26 \\
\pm \\
0.14^{b}\end{array}$ & $\begin{array}{l}5.61 \pm \\
0.15^{d}\end{array}$ & $\begin{array}{l}6.07 \\
\pm \\
0.16^{d}\end{array}$ & $\begin{array}{l}5.82 \\
\pm \\
0.14^{d}\end{array}$ & $\begin{array}{l}2.15 \pm \\
0.14^{\mathrm{e}}\end{array}$ & $\begin{array}{l}2.45 \\
\pm \\
0.18^{\mathrm{e}}\end{array}$ & $\begin{array}{l}2.24 \\
\pm \\
0.15^{\mathrm{e}}\end{array}$ \\
\hline $\begin{array}{l}\text { ZSTS } \\
(\mathrm{km})\end{array}$ & $\begin{array}{l}11.58 \pm \\
0.07^{\mathrm{a}}\end{array}$ & $\begin{array}{l}11.60 \\
\pm \\
0.08^{a}\end{array}$ & $\begin{array}{l}11.40 \\
\pm \\
0.09^{a}\end{array}$ & $\begin{array}{l}7.60 \pm \\
0.06^{\mathrm{b}}\end{array}$ & $\begin{array}{l}7.54 \\
\pm \\
0.07^{b}\end{array}$ & $\begin{array}{l}7.56 \\
\pm \\
0.08^{b}\end{array}$ & $\begin{array}{l}3.85 \pm \\
0.05^{c}\end{array}$ & $\begin{array}{l}3.83 \\
\pm \\
0.07^{\mathrm{c}}\end{array}$ & $\begin{array}{l}3.90 \\
\pm \\
0.06^{\mathrm{c}}\end{array}$ \\
\hline
\end{tabular}

Paper A: 100\% SB; Paper B: SB: CH (50:50); Paper C: 100\% CH; CC: chitosan coated; WC: chitosan-beeswax coated

This clearly reveals that corn husk fibers alone produce the lowest strength and inter-fiber bonding, thus, providing scope for its blending with other stronger natural fibers. Blending of pulps from underexplored agricultural wastes and pulps from other non-wood materials or agro-wastes would contribute to the improvement of the paper strength properties. Ample literature also states that blending of long-fibered pulp with short fibred pulp for the development of papers with appreciable properties is considered an important aspect in papermaking [27-29].

Post coating: Papers are generally attributed to poor strength and barrier properties when compared to plastics. Thus, coatings are applied to enhance their functionalities. Table 2 shows the mechanical strength properties of developed handsheets post coating. Chitosan-coated handsheets are designated as (CC) and beeswaxchitosan emulsion-based coatings were referred to as (WC). The burst index for chitosan-coated papers increased significantly by approximately $60-80 \%$. To be precise, the burst strength for papers $A, B$ and $C$ increased $82.5 \%, 59.42 \%$ and $58.46 \%$ in relation to uncoated ones. Likewise, a significant increase $(p<0.05)$ in the tear strength and tensile strength was also observed for all chitosan-coated samples, irrespective of the pulp formulation. For this reason, it fetched a higher breaking length indicating that chitosan-coated papers shall be difficult to break under an applied force, as compared to uncoated counterparts. This could be attributed to the dispersion of chitosan particles into the interfibrillar space of the fiber matrix. It is well 
concluded that chitosan coating improved the bond strength between fibers in the paper. This has also been confirmed by Prasetiyo et al [30] who affirmed that the coating might have undergone slight penetration into the matrix during cold pressing. Chitosan and cellulose have striking structural resemblance and thus, show high compatibility and affinity to be absorbed onto cellulosic fibrous surfaces. Due to its good film forming properties, and the association of reactive amino group and hydroxyl groups of chitosan to form hydrogen bonds with cellulosic surfaces, it is considered a promising coating component that contributes to paper strength and barrier [31]. However, beeswax coatings did not seem to contribute significantly to the mechanical strength of the papers. Hendrawati et al [32] and Khwaldia et al [33] also reported that wax-based coatings did not show any significant effect on the burst, tensile and tear properties of paper-based materials.

\section{Barrier properties: porosity, water absorptiveness, water vapor permeability}

Sheet porosity is the measure of airflow through a known area of paper and is an indicator of the potential absorbency of paper, particularly for the coated grade [34]. Irrespective of the paper composition, air permeance of all handsheets decreased significantly $(p<0.05)$ when coated with chitosan and chitosan-beeswax emulsion, while the uncoated ones gave the highest porosity values. Likewise, Cobb value, one of the critical parameters affecting the structural integrity of papers, is used as a measure of the water absorptiveness of paper and paperboard-based packaging materials [35]. All control samples demonstrated a higher cob value signifying higher water absorptivity and retention by the paper substrates. While, chitosan and beeswax coated papers showed relatively lower cobb values that are suggestive of resistance to water penetration and retention. The barrier properties of coated and control samples are mentioned in Table 3.

Table 3

Barrier properties of handsheets (pre and post coating)

\begin{tabular}{|c|c|c|c|c|c|c|c|c|c|}
\hline \multirow[t]{2}{*}{ Parameters } & \multicolumn{3}{|l|}{ A } & \multicolumn{3}{|l|}{ B } & \multicolumn{3}{|l|}{ C } \\
\hline & Uncoated & CC & WC & Uncoated & CC & WC & Uncoated & CC & wC \\
\hline $\begin{array}{l}\text { Cobb value } \\
\left(\mathrm{g} \mathrm{m}^{-2}\right)\end{array}$ & $\begin{array}{l}55.7 \pm \\
0.43^{d}\end{array}$ & $\begin{array}{l}30.7 \\
\pm \\
0.50^{f}\end{array}$ & $\begin{array}{l}10.0 \\
\pm \\
0.55^{\mathrm{h}}\end{array}$ & $\begin{array}{l}79.5 \pm \\
0.64^{c}\end{array}$ & $\begin{array}{l}34.2 \\
\pm \\
0.50^{\mathrm{e}}\end{array}$ & $\begin{array}{l}12.9 \\
\pm \\
0.39 \mathrm{~g}\end{array}$ & $\begin{array}{l}110.1 \pm \\
0.79^{a}\end{array}$ & $\begin{array}{l}83.0 \\
\pm \\
0.68^{\mathrm{b}}\end{array}$ & $\begin{array}{l}31.5 \\
\pm \\
0.52^{f}\end{array}$ \\
\hline $\begin{array}{l}\text { Water vapor } \\
\text { permeability } \\
\left(\mathrm{gm}^{-1} \mathrm{~s}^{-1} \mathrm{P}^{-1}\right)\end{array}$ & $\begin{array}{l}3.4 \pm \\
0.05^{\mathrm{a}}\end{array}$ & $\begin{array}{l}3.1 \pm \\
0.03^{\mathrm{ab}}\end{array}$ & $\begin{array}{l}2.9 \pm \\
0.05^{b}\end{array}$ & $\begin{array}{l}3.5 \pm \\
0.04^{\mathrm{a}}\end{array}$ & $\begin{array}{l}3.3 \pm \\
0.06^{\mathrm{a}}\end{array}$ & $\begin{array}{l}2.8 \pm \\
0.05^{b}\end{array}$ & $\begin{array}{l}3.9 \pm \\
0.06^{\mathrm{a}}\end{array}$ & $\begin{array}{l}3.6 \pm \\
0.04^{\mathrm{a}}\end{array}$ & $\begin{array}{l}3.2 \pm \\
0.04^{\mathrm{a}}\end{array}$ \\
\hline $\begin{array}{l}\text { Porosity (air } \\
\text { permeance) } \\
\left(\mathrm{ml} \mathrm{min}{ }^{-1}\right)\end{array}$ & $\begin{array}{l}12.00 \pm \\
0.12^{\mathrm{c}}\end{array}$ & $\begin{array}{l}7.93 \\
\pm \\
0.12^{\mathrm{e}}\end{array}$ & $\begin{array}{l}2.90 \\
\pm \\
0.11^{\mathrm{g}}\end{array}$ & $\begin{array}{l}7.00 \pm \\
0.14^{f}\end{array}$ & $\begin{array}{l}1.76 \\
\pm \\
0.11^{\mathrm{h}}\end{array}$ & $\begin{array}{l}1.00 \\
\pm \\
0.10^{\mathrm{i}}\end{array}$ & $\begin{array}{l}30.00 \pm \\
0.12^{\mathrm{a}}\end{array}$ & $\begin{array}{l}21.90 \\
\pm \\
0.14^{\mathrm{b}}\end{array}$ & $\begin{array}{l}10.59 \\
\pm \\
0.11^{d}\end{array}$ \\
\hline
\end{tabular}

Values having different superscripts differ significantly $(p<0.05)$ column-wise

Paper A: 100\% SB; Paper B: SB: CH (50:50); Paper C: 100\% CH; CC: chitosan coated; WC: chitosan-beeswax coated 
Uncoated cellulose papers had the highest water absorptivity and air permeance, due to the presence of free $\mathrm{OH}$ groups, providing a hydrophilic character to the paper. Chitosan coating resulted in a significant reduction $(p<0.05)$ in water absorptivity and air permeance respectively, in comparison to uncoated papers. Chitosan is known to decrease water absorption and air permeability by increasing the contact angle between the water droplet and the paper surface $[7,35,36]$. Beeswax-chitosan coating enormously decreased the water absorptiveness of paper A, B and C to $82.04 \%, 83.7 \%$ and $71.38 \%$ respectively, in relation to uncounted ones. The air permeance of beeswax coated handsheets also showed a decline by $75.8 \%, 85.7 \%$ and $64.7 \%$ respectively. This decrease was very much significant $(p<0.05)$. As stated previously, the hydrophilic nature of cellulosic fibers (attributed to the presence of $-\mathrm{OH}$ groups) and porous interfibrillar network allows higher penetration of water molecules. The coating process, however, facilitates penetration of bio-coating solutions into void spaces between the matrix or their deposition over the surfaces, thus imparting a hindrance to easy water absorption. This is also confirmed by SEM images (Fig. 3) that demonstrate the presence of coatings onto the fibrous substrates, lessening the interfiber distance and by this means, decreasing the porosity. Similar results were also reported by lewkittayakorn et al. [5], Zhang et al (2014a) [20] and Zhang et al (2014b) [37], who accredited the reduction in porosity (in terms of water and air permeation) to deposition of hydrophobic coating substances within/on the fiber matrix, upon application of such coatings onto the paper substrates. Another study by Zhang et al (2017) [6] also demonstrated improvement in water vapor barrier properties of the paper surface due to hydrophobic characteristics of beeswax as it tends to partially fill in the network gaps.

Another crucial factor that governs spoilage of a product during storage is the water vapor permeability (WVP) characteristics of the packaging material. Surface coatings aim at providing hindrance and reducing water exchange between the environment and stored food products (Priyadarshi et al. 2020) [38]. As observed in Table 3, all coated paper samples had a significantly $(p<0.05)$ lower WVP value in comparison to the uncoated ones. The highest reduction in the values was evident for beeswax-chitosan-coated papers, suggesting probable penetration of coating solutions into void spaces between the fiber matrix during coating or pressing operations. Sothornvit (2009) [39] also reported a major decrease in WVP of paper samples coated with hydrocolloid in combination with beeswax, suggesting applicability in the medical as well as food industry. The values thus obtained were still higher than that of PE-coated paper as reported by Shankar and Rhim (2018) [40] owing to the fact that plastic-based coatings have much higher resistance to moisture and water vapor. Thus, we propose our packaging material for products that are not highly sensitive to moisture.

Finally, it was found that both types of bio-coatings had a significant effect on the barrier properties of developed papers from all three formulations. The barrier properties against water vapor, moisture and air were strongest with beeswax chitosan emulsion coating.

\section{Surface characterization of handsheets using SEM}

The surface topography of uncoated and coated handsheets were investigated using scanning electron microscopy (SEM, Everhart-Thornley detector; Zeiss EVO 50, Germany). The strength of the fiber matrix can be anticipated based on the compactness of the fibers. Figure 1 shows images of Paper A, B and C (coated and uncoated). Figures 2 show longer closely packed fibers that may also be correlated with the strength properties of handsheets. The furnish blend of the fibers (paper B) showed an optimum arrangement of longer and shorter fibers. Microstructure of uncoated papers exhibited a highly uneven and rough surface made up of interwoven visible fibers and void spaces. This dense network of entwined fibers was much noticeable in 
uncoated samples, while the images showed a continuous layer when coated with chitosan or beeswax emulsions. Beeswax emulsions were seen as a mat of spherical globules of varying diameters ranging between 10-15 $\mu \mathrm{m}$. Both the cases also might have allowed the penetration of chitosan and beeswax emulsion easily into voids of the sheet matrix, leading to high tensile strength and increased water resistance. Reis et al [19] also suggested that the chitosan chains are able to modify the surface of uncoated papers, filling the interfibrillary cellulose spaces and forming smooth surfaces. The results given by Kopacic et al. [35] and Wang and Jing [7] on different chitosan coated paper substrates are also in accordance with the obtained SEM results in our study. The results can be correlated with the significant decrease in air permeance and water absorptivity of the handsheets, where a thicker barrier is observed due to the presence of bio-coatings.

\section{Biodegradation studies}

The biodegradation rate, expressed as \% weight loss of the paper strips are presented in Fig. 4.

\begin{tabular}{|lllllllllll|}
\hline Weight loss (\%) & A & \multicolumn{3}{c|}{ B } & \multicolumn{1}{c|}{ C } \\
\hline Days & Uncoated & CC & WC & Uncoated & CC & WC & Uncoated & CC & WC \\
\hline 0 & & & & & & & & & & \\
\hline 10 & 75 & 30 & 15 & 70 & 38 & 20 & 85 & 44 & 14 \\
20 & 10 & 65 & 35 & 29 & 59 & 40 & 20 & 70 & 45 \\
30 & - & 12 & 55 & & 20 & 60 & - & 21 & 60 \\
40 & - & - & 22 & & - & 15 & - & - & 25 \\
\hline 50 & - & - & 5 & & - & 5 & - & - & 7 \\
\hline
\end{tabular}

Figure 4 shows the photographs of coated and uncoated paper samples, during biodegradation study, taken every 10th day. It was observed that all control (uncoated) paper samples achieved a higher biodegradation rate as compared to chitosan and beeswax coated papers. This could be attributed to the absence of any cross-linking agents, additives, or coatings during the handsheet formation that would otherwise have elongated the degradation process. Uncoated papers disintegrated into pieces and decomposed the fastest, i.e. within 6 weeks (30 days) while coated sheets remained relatively intact. The enzymes produced by soil microbiota are responsible for biodegradation and cellulose can be easily digested by the action of endo and exo-cellulases, produced by bacteria/fungi [41]. Thus, chitosan and beeswax coated samples exhibited lower degradation rates in soil, due to presence of an additional coating layer onto the base paper which prevented direct attack of digesting enzymes on the material. Chitosan and beeswax coated papers achieved complete degradation in about 40-50 days. It may be inferred that in order to degrade the paper, the soil microbiota needs to degrade the coating layer first followed by base paper. As evident from SEM results, cross-linking induced by the penetration of chitosan and beeswax into the cellulose matrix (base paper) could be another reason of resistance to microbial digestion and delayed bio-degradation. Similar results have been shown by Nurul Syahida et al [18] on gelatine/palm wax/lemongrass essential oil coated paper which showed lower biodegradation rate in comparison to the control. lewkittayakorn et al [5] also suggested minimum degradation 
time for uncoated paper developed from pineapple leaf pulp and a relatively higher duration for chitosanbeeswax coated paper for the similar reasons.

\section{Conclusion}

This research proposes and establishes the use of agricultural fibers for development of biodegradable packaging material intended for commercial use. All pulp formulations from $\mathrm{SB}$ and $\mathrm{CH}$, were acceptable for making paper of various grades, in terms of physico-mechanical properties, that may be utilized for diverse packaging applications. $\mathrm{CH}$ can definitely be utilized as a viable raw material for the pulp and paper industry while blending it with other agro-residues can enhance its suitability and applicability for high strength packaging applications. Chitosan and chitosan-beeswax coated handsheets demonstrated appreciable improvement in barrier properties (water absorptivity, water vapor permeability as well as air permeance), thus providing a scope for paper based packaging of miscellaneous products. The results advocated for beeswaxchitosan emulsion as the best among the coatings tested, for coating cellulose papers to enhance their barrier properties.

\section{Declarations}

\section{Declaration of Competing Interest}

The authors have declared no conflicts of interest for this research article.

\section{References}

1. NPMCR (2019) Available online: http://agricoop.nic.in/sites/default/files/NPMCR_1.pdf

2. Barman M, Mukhopadhyay A Stubble burning in India: Problems and mitigation strategies.Agri food enewsletter2(12),562-564

3. Bhardwaj A, Alam T, Sharma V, Alam MS, Hamid H, Deshwal GK (2020) Lignocellulosic agricultural biomass as a biodegradable and eco-friendly alternative for polymer-based food packaging.J Packag Technol Res1-12

4. Liu Z, Wang H, Hui L (2018) Pulping and papermaking of non-wood fibers. Pulp and Paper Processing 15:44

5. lewkittayakorn J, Khunthongkaew P, Wongnoipla Y, Kaewtatip K, Suybangdum P, Sopajarn A (2020) Biodegradable plates made of pineapple leaf pulp with biocoatings to improve water resistance. $J$ Mater Res Technol 9(3):5056-5066

6. Zhang N, Xu J, Gao X, Fu X, Zheng D (2017) Factors affecting water resistance of alginate/gellan blend films on paper cups for hot drinks. Carbohyd Polym 156:435-442

7. Wang S, Jing Y (2016) Effects of a chitosan coating layer on the surface properties and barrier properties of kraft paper. BioResour 11(1):1868-1881

8. Vikele L, Laka M, Sable I, Rozenberga L, Grinfelds U, Zoldners J, Passas R, Mauret E (2017) Effect of chitosan on properties of paper for packaging. Cellulose ChemTechnol 51:67-73 
9. Andrade MF, Colodette JL (2014) Dissolving pulp production from sugar cane bagasse. Ind Crops Prod $52: 58-64$

10. ISO 5264-2:2011, Pulps - Laboratory beating - Part 2:PFI mill method

11. ISO 5269-1:2005, Pulps - Preparation of laboratory sheets for physical testing - Part 1:Conventional sheet-former method

12. ISO 1924-2:2008, Paper and board -Determination of tensile properties

13. ISO 15754 (2009) Paper and board -. Determination of Z-directional tensile strength

14. ISO 2758:2014,Paper - Determination of bursting strength

15. ISO 1974:2012, Paper - Determination of tearing resistance - Elmendorf method

16. ISO 5636-5:2013, Paper and board - Determination of air permeance (medium range) - Part 5:Gurley method

17. ISO 535 (2014) Paper and board -. Determination of water absorptiveness - Cobb method

18. Nurul Syahida S, Ainun ZM, Ismail-Fitry MR, Nur Hanani ZA (2020) Development and characterisation of gelatine/palm wax/lemongrass essential oil (GPL)-coated paper for active food packaging. Packag Technol Sci 33(10):417-431

19. Reis AB, Yoshida CM, Reis APC, Franco TT (2011) Application of chitosan emulsion as a coating on Kraft paper. Polym Int 60(6):963-969

20. Zhang W, Xiao H, Qian L (2014a) Enhanced water vapour barrier and grease resistance of paper bilayercoated with chitosan and beeswax. Carbohyd Polym 101:401-406

21. Yaradoddi JS, Banapurmath NR, Ganachari SV, Soudagar MEM, Mubarak NM, Hallad S, Hugar S, Fayaz H (2020) Biodegradable carboxymethyl cellulose based material for sustainable packaging application. Sci Rep 10(1):1-13

22. Polat S, Uslu MK, Aygün A, Certel M (2013) The effects of the addition of corn husk fibre, kaolin and beeswax on cross-linked corn starch foam. J Food Engineer 116(2):267-276

23. Chaireh S, Ngasatool P, Kaewtatip K (2020) Novel composite foam made from starch and water hyacinth with beeswax coating for food packaging applications. Int J of Biol Macromol 165:1382-1391

24. Alagbe EE, Bassey ES, Daniel OE, Shongwe MB, Ojewumi ME, Igwe CC (2019) Physical, chemical and mechanical properties of corn sheath as pulp and paper raw material. In Journal of Physics: Conference Series (Vol. 1378, No. 3, p. 032083). IOP Publishing

25. Kamel S, El-Sakhawy M, Nada AMA (2004) Mechanical properties of the paper sheets treated with different polymers. Thermochimica acta 421(1-2):81-85

26. Kontturi KS, Lee KY, Jones MP, Sampson WW, Bismarck A, Kontturi E (2021) Influence of biological origin on the tensile properties of cellulose nanopapers. Cellulose, pp 1-10

27. Fahmy Y, Fahmy TYA, Mobarak F, El-Sakhawy M, Fadl MH (2017) Agricultural residues (wastes) for manufacture of paper, board, and miscellaneous products: Background overview and future prospects. Int J ChemTech Res 10(2):424-448

28. Turk K, Oztekin E, Kina C (2019) Self-compacting concrete with blended short and long fibres: experimental investigation on the role of fibre blend proportion.European J Environ Civil Engineer,1-14 
29. Abd El-Sayed ES, El-Sakhawy M, El-Sakhawy MAM (2020) Non-wood fibers as raw material for pulp and paper industry. Nordic Pulp Paper Res J 35(2):215-230

30. Prasetiyo KW, Zulfiana D, Anita SH, Fatriasari W, Suryanegara L, Masruchin N, Gutari S (2020) Effects of chitosan coating on the physical, mechanical and antimicrobial properties of food packaging paper. Jurnal Sains Materi Indonesia 21(2):62-68

31. Zakaria S, Chia CH, Ahmad WW, Kaco H, Chook SW, Chan CH (2015) Mechanical and antibacterial properties of paper coated with chitosan. Sains Malaysia 44:905-911

32. Hendrawati N, Wibowo AA, Chrisnandari RD, Adawiyah R (2020) February. Biodegradable foam tray based on sago starch with beeswax as coating agent. In IOP Conference Series: Materials Science and Engineering (Vol. 1073, No. 1, p. 012006). IOP Publishing

33. Khwaldia K (2010) Water Vapor Barrier and Mechanical Properties of Paper-Sodium Caseinate and PaperSodium Caseinate-Paraffin Wax Films. J Food Biochem 34:998-1013

34. Kirwan MJ (ed) (2012) Handbook of paper and paperboard packaging technology. John Wiley \& Sons

35. Kopacic S, Walzl A, Zankel A, Leitner E, Bauer W (2018) Alginate and chitosan as a functional barrier for paper-based packaging materials. Coatings 8(7):235

36. Bhardwaj A, Sharma N, Sharma V, Alam T, Sahu JK, Hamid H (2021) Assessing the consumer acceptance and storability of chitosan and beeswax coated cellulose packaging for whole wheat bread.Food Control,108682

37. Zhang WW, Qian LY, Xiao HN (2014b) Hydrophobicity of Beeswax-Chitosan Latex Coated Paper. In Advanced Materials Research, Trans Tech Publications Ltd. Vol. 936: 1077-1081

38. Priyadarshi R, Rhim JW (2020) Chitosan-based biodegradable functional films for food packaging applications. Innov Food Sci Emerg Technol 62:102346

39. Sothornvit R (2009) Effect of hydroxypropyl methylcellulose and lipid on mechanical properties and water vapor permeability of coated paper. Food Res Int 42(2):307-311

40. Shankar S, Rhim J-W (2018) Antimicrobial wrapping paper coated with a ternary blend of carbohydrates (alginate, carboxymethyl cellulose, carrageenan) and grapefruit seed extract. Carbohyd Polym 196:92-101

41. Júnior AV, Fronza N, Foralosso FB et al (2014) Biodegradable duofunctional active film: antioxidant and antimicrobial actions for the conservation of beef. Food Bioprocess Technol 8(1):75-87

\section{Figures}




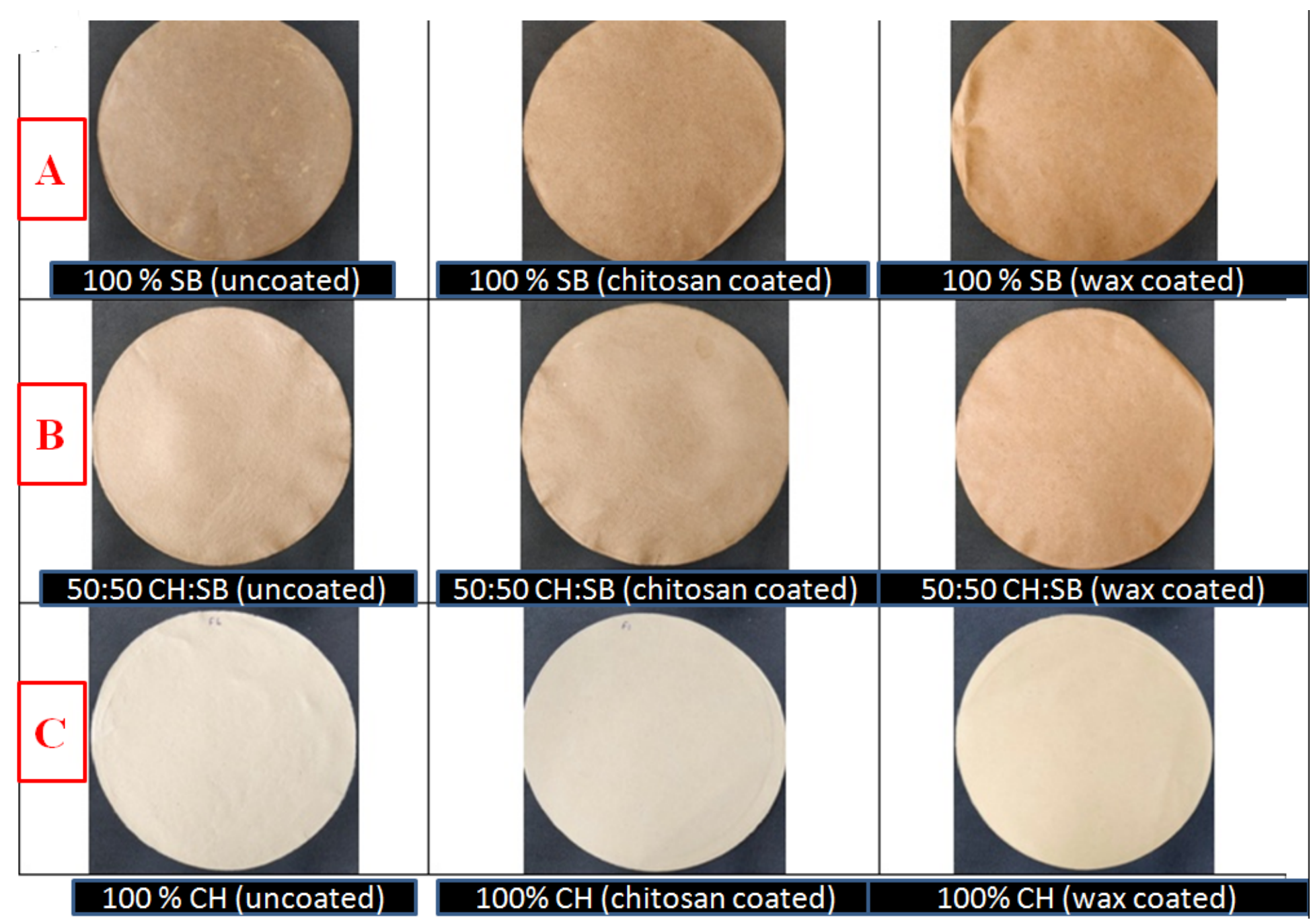

Figure 1

Handsheets $\left(80 \mathrm{~g} / \mathrm{m}^{2}\right)$ developed from sugarcane bagasse (SB) and corn husk (CH) in varying proportions; uncoated and with applied coating solutions. (Reproduced from Bhardwaj et al. 2021) 


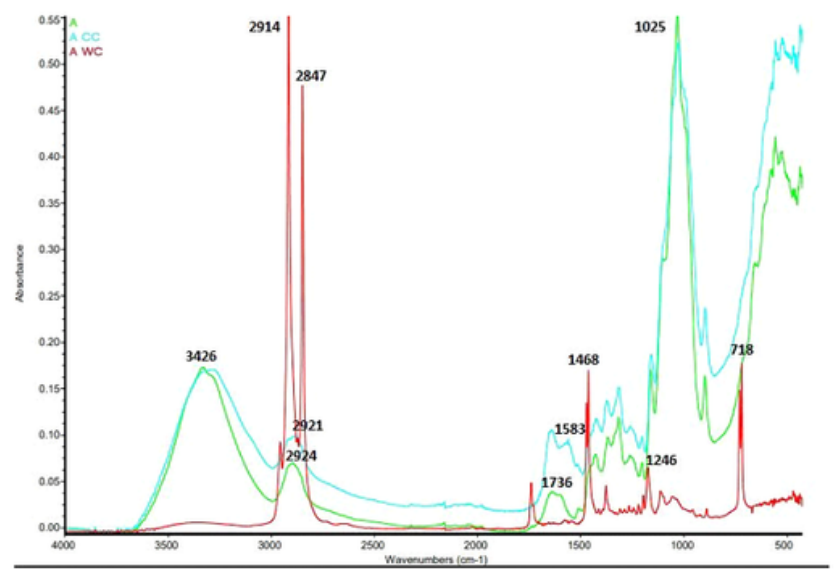

(a)

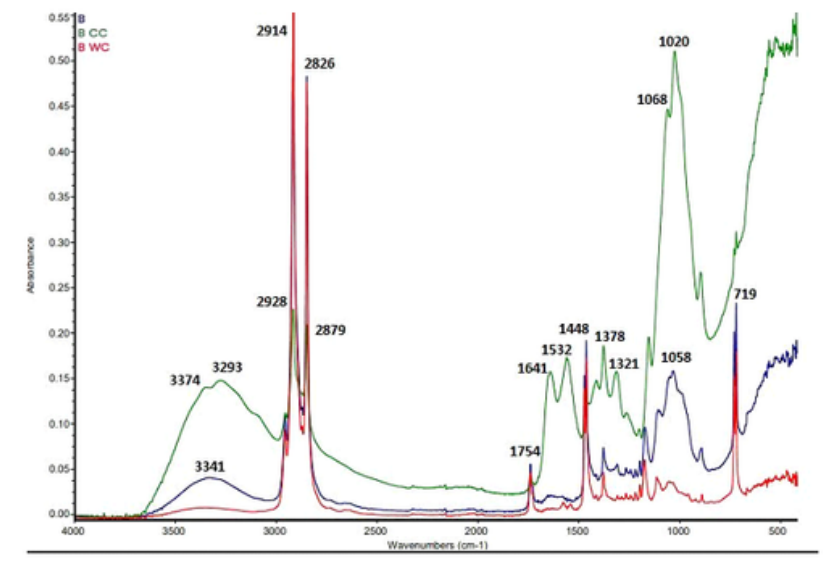

(b)

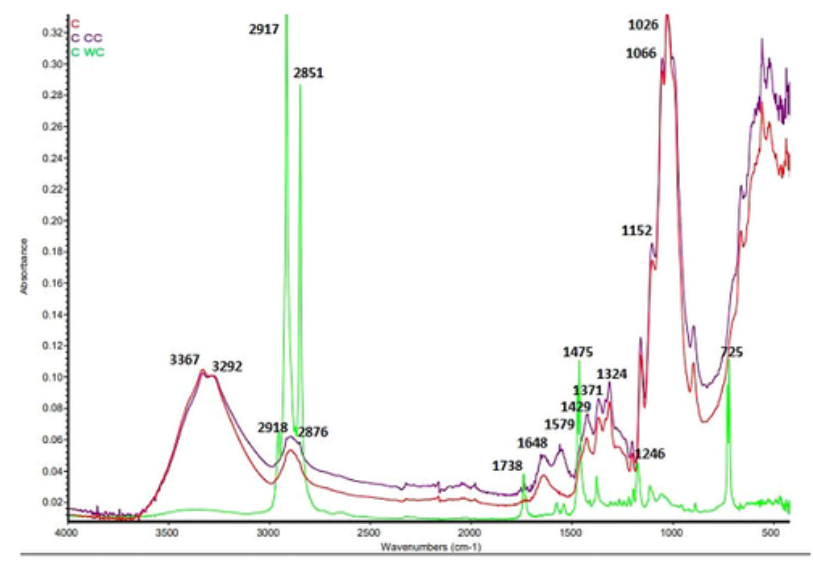

(c)

Figure 2

FTIR spectra of developed paper samples

(a): A: uncoated; A CC: chitosan coated paper A; A WC: Beeswax coated Paper A

(b): B: uncoated; B CC: chitosan coated paper B; B WC: Beeswax coated Paper B

(c): C: uncoated; C CC: chitosan coated paper C; C WC: Beeswax coated Paper 


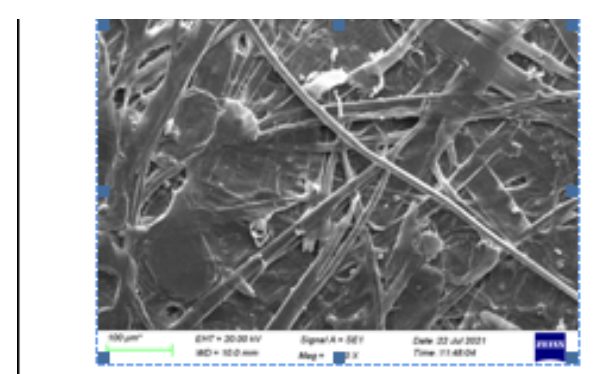

(a)

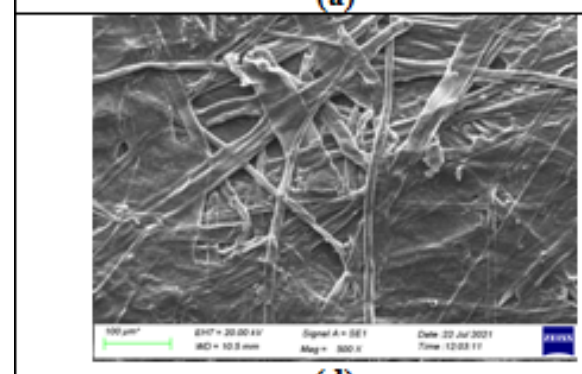

(d)

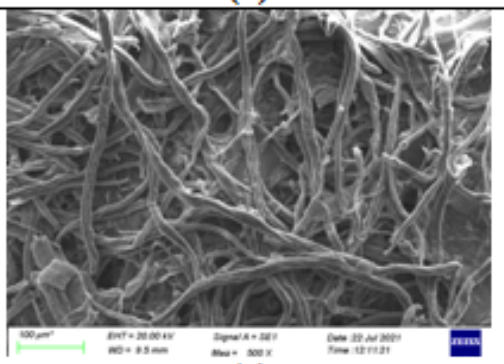

(g)

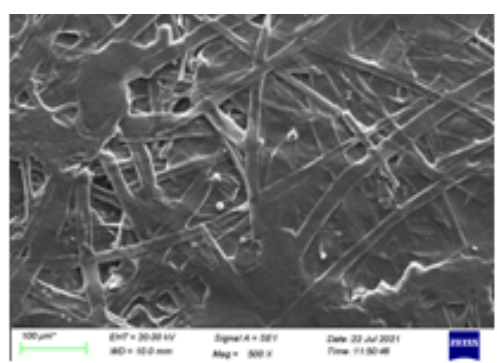

(b)

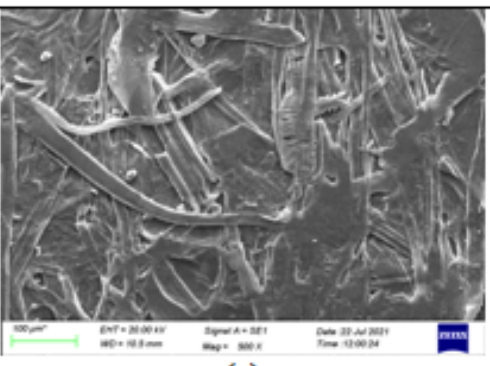

(e)

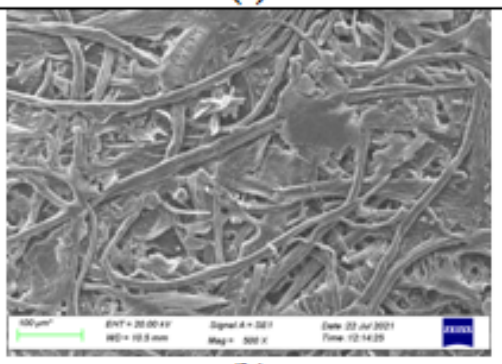

(h)

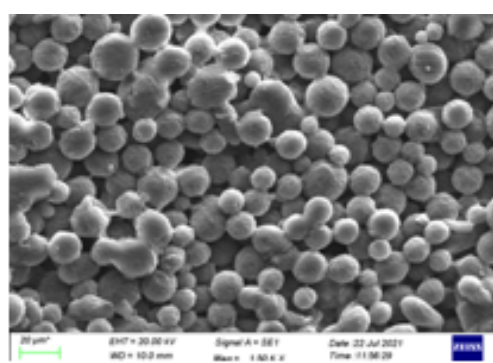

(c)

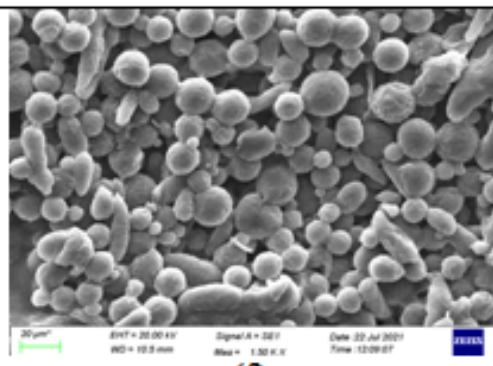

(f)

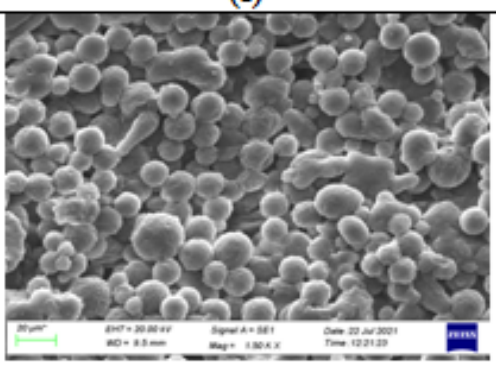

(i)

Figure 3

Surface morphology (SEM images) of uncoated and coated handsheets [(a-c): Uncoated, chitosan coated and wax coated Paper A] [(d-f): Uncoated, chitosan coated and wax coated Paper B] [(g-i): Uncoated, chitosan coated and wax coated Paper C 


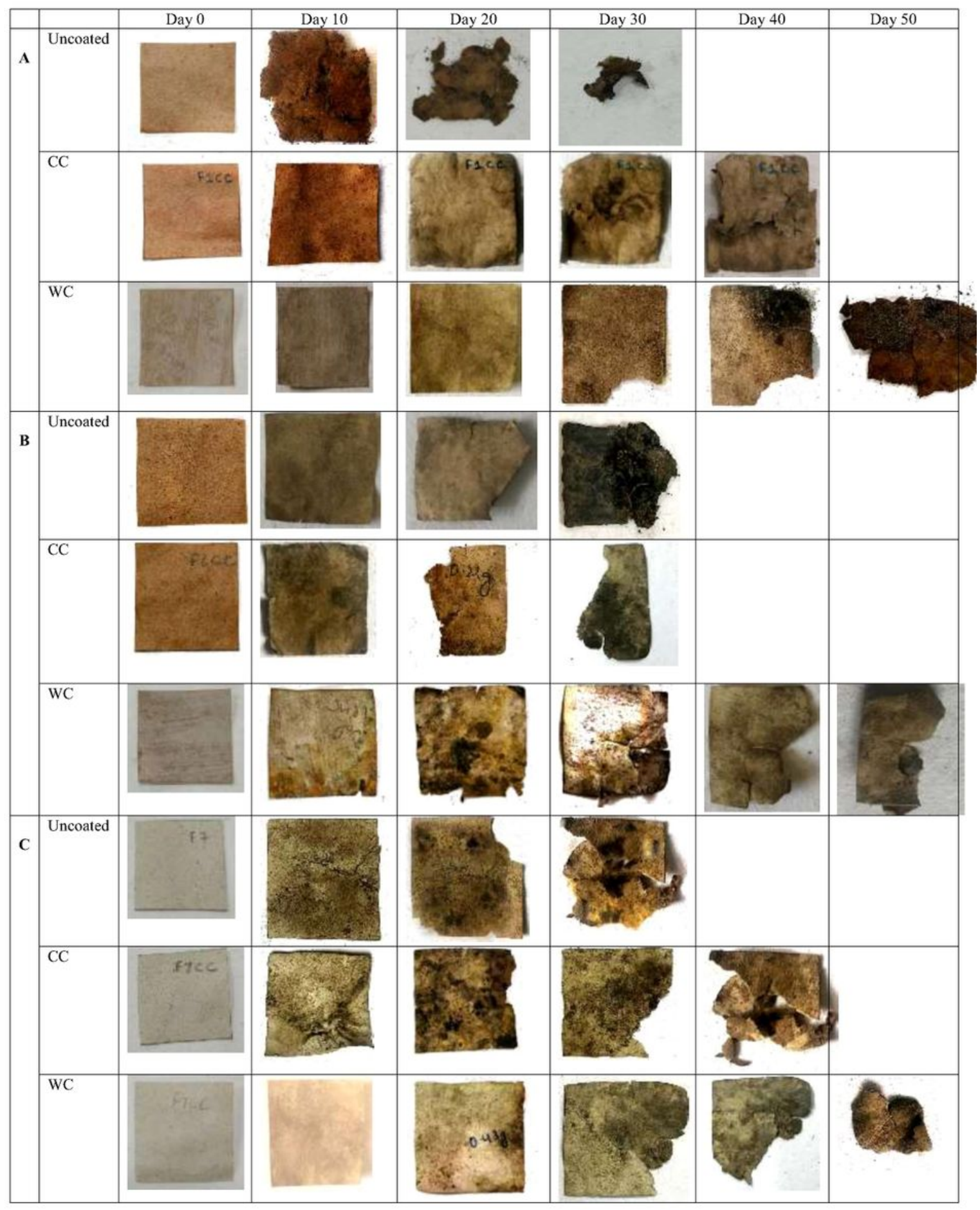

Figure 4

Physical changes in coated and uncoated papers made of SB and $\mathrm{CH}$ pulp with respective coatings, during degradation for 50 days (photos taken every $10^{\text {th }}$ day)

(A: $100 \%$ SB; B: $50: 50$ SB: CH; C: $100 \%$ CH) 